Claves. Revista de Historia, Vol. 5, $\mathrm{N}^{\circ} 8$

Montevideo, enero - junio 2019

(pp. 35 - 65) ISSN 2393-6584

DOI: http://dx.doi.org/10.25032/crh.v5i8.3

\title{
Los trabajadores de las grandes tiendas: Gath y Chaves, Chile, 1910-1952
}

\author{
Department Store Workers: Gath \& Chaves, Chile, 1910-1952
}

Ángela Vergara

California State University, Los Angeles

Paola Orellana Valenzuela

Universidad de Chile

Recibido: 03/05/2019

Aceptado: 06/07/2019

Resumen. En este artículo, se examinan las experiencias de trabajo, sindicalización, y participación política de los trabajadores en una cadena de grandes almacenes de capital británico en Chile, The South American Store Gath y Chaves, entre 1910 y 1952. Desde la perspectiva de la historia trasnacional y de los estudios laborales, se busca comprender la influencia del capital extranjero en las identidades laborales, la circulación de nuevas prácticas de consumo y organización de la mano de obra, y los esfuerzos de los trabajadores por transcender espacios locales y nacionales. Aunque la investigación se centra en el caso chileno, se explora su historia dentro de una cadena comercial que tenía su centro neurálgico en Buenos Aires. Así, se destacan tres aspectos de esta historia: (1) las características del capital retail británico durante la primera mitad del siglo XX; (2) la estructura laboral al interior de la casa comercial; (3) las experiencias de sindicalización y solidaridad internacional (específicamente los vínculos entre los sindicatos chilenos y argentinos entre 1948-1952).

${ }^{1}$ Agradecemos la colaboración de Hernán Díaz en la recopilación de periódicos en Buenos Aires, Argentina. 
Palabras Clave: Grandes almacenes, huelgas, historia del trabajo, solidaridad internacional.

Abstract. This article examines the work, unionization, and political experiences of retail workers in The South American Store Gath and Chaves, a British-owned department store in Santiago, between 1910 and 1952. From the perspective of transnational labor history, it explores the influence of foreign capital on workers' identity, the circulation of new consumption practices and labor management ideas, and the efforts of workers to cross local and national boundaries. Building on the Chilean case, this article also places this story into the larger history of a retail businesses that had its center in Buenos Aires. It addresses three main topics: (1) The characteristics of British retail capital during the first half of the twentieth century; (2) The organization of the workforce and the working space in Santiago; and (3) the experience of unionization and building of international relations (specifically the relationship between Chilean and argentine unions between 1948-1952).

Key words: Department Stores, strikes, labor history, international solidarity

\section{Introducción}

Entre 1910 y 1952, la Casa Gath y Chaves era una de las tiendas más renombradas de la capital chilena. Su edificio de cinco pisos, con ascensores y estructura de fierro y concreto, ubicado en la concurrida esquina de las calles Huérfanos y Estado constituía un espacio de encuentro de la elite y las clases medias emergentes. Las crónicas locales destacaban sus elegantes vitrinas, surtido de productos que iban desde artículos de menaje hasta calzado y juguetes, y su exclusivo salón de té (tea room) donde músicos y orquestas de baile amenizaban las tardes. En otras palabras, Gath y Chavés ofrecía a las clases acomodadas chilenas una experiencia urbana y de consumo cosmopolita que se asemejaba a Buenos Aires y las grandes capitales europeas. Si la historiografía ha destacado como las grandes tiendas transformaron la fisionomía de la ciudad y las prácticas de consumo, las experiencias de los trabajadores del comercio han sido escasamente estudiadas. Este vacío no es accidental, pero, en parte, reproduce la imagen 
trasmitida por las propias casas comerciales. Las grandes tiendas desarrollaron tempranamente formas de control paternalista que incluían una serie de beneficios y regalías sociales, un sistema de trabajo que se manifestaba en la organización del espacio físico y ocultaba la realidad de quienes fabricaban, cocinaban, distribuían, y vendían los productos.

El caso de Gath y Chaves nos permite repensar la historia del consumo desde la perspectiva de América Latina, los vínculos trasnacionales, y el mundo del trabajo. La historia sobre el consumo ha crecido enormemente en la última década abarcando diversos temas tales como los anuncios comerciales, la influencia extranjera, el papel de las mujeres, la relación entre consumo, progreso, y modernidad, y, más recientemente, la participación de los trabajadores en el mercado ${ }^{2}$. Dentro de estos debates, las grandes tiendas, las "catedrales del progreso" como las llamaron Geoffrey Crossick y Serge Jaumain, simbolizaban las profundas transformaciones sociales, culturales, y económicas asociadas al surgimiento de una sociedad de consumo en el mundo industrializado3.

Las grandes tiendas también fueron importantes espacios de trabajo. Michael Miller en su clásico estudio sobre Bon Marché, el almacén más emblemático del Paris de la Belle Époque, señalaba la importancia de estudiar estos nuevos espacios de consumo desde la perspectiva de la historia social. Reflejo de un mundo burgués en transformación, la gran tienda, explica Miller, reflejaba los cambios en la organización del capital comercial, los patrones de venta y consumo, y también las características de la mano de

${ }^{2}$ La historiografía sobre consumo y América Latina es amplia. La revista Historia Crítica dedicó un número especial (núm. 65, año 2017) a este tema, los artículos de Inés Pérez y Ana María Otero Cleves, entre otros, dan cuenta del estado de este campo de estudio. Por su parte, Enriqueta Quiroz ha examinado los diferentes desafíos metodológicos e historiográficos de la historia del consumo. Sobre el tema de los trabajadores y consumo en América Latina: MILANESIO, Natalia, Cuando los trabajadores salieron de compras: nuevos consumidores, publicidad, y cambio cultural durante el primer peronismo, Buenos Aires, Editorial siglo XXI, 2014.

3 CROSSICK, Geoffrey; JAUMAIN, Serge, Cathedrals of Consumption: The European Department Store, 1850-1939, Brookfield, VT, Ashgate. 1999; LANCASTER, William. The Department Store: A Social History, London, New York, Leicester University Press, 1995; MILLER, Michael B., The Bon Marché: Bourgeois Culture and the Department Store, 1869-1920, Princeton, Princeton University Press, 1981. Sobre América Latina véase: BUNKER, Steven B., Creating Mexican Consumer Culture in the Age of Porfirio Díaz, Albuquerque, University of New Mexico Press, 2012; DUSSAILLANT, Jacqueline, Las reinas de Estado: consumo, grandes tiendas y mujeres en la modernización del comercio de Santiago (1880 1930); Santiago, Ediciones Universidad Católica, 2011; GUY, Donna, "Producción, ventas y consumo: reflexiones sobre el papel del género en las tiendas grandes de Buenos Aires, 1883-1930”, Descentrada, vol. 2, núm. 1, 2018. 
obra y las relaciones y experiencias de trabajo ${ }^{4}$. Estudios más recientes se han enfocado en las vendedoras como símbolo de la feminización del empleo urbano, demostrando que los estereotipos de género también influyeron sobre los sistemas de control y organización de la mano de obra 5 . Asimismo, algunos trabajos han enfatizado las relaciones paternalistas al interior de las tiendas, prácticas que contribuyeron a la relativa aquiescencia de sus trabajadores ${ }^{6}$. A pesar de estas contribuciones, el tema del trabajo dentro de las grandes tiendas continúa relegado a segundo plano y, especialmente, aquellas preguntas que tienen relación con el conflicto social y la protesta. Gran parte de los estudios se concentran en los comienzos del siglo XX, sin hacerse cargo de cómo estos espacios de trabajo se transformaron a lo largo del siglo.

El modelo de las grandes tiendas también fue exportado al resto del mundo, donde se adaptó a las características y tradiciones locales. Sin embargo, señala Nancy Reynolds para el caso de Egipto, las grandes tiendas no replicaron automáticamente el sistema europeo, sino que se adaptaron a las características de la población local, creando un modelo híbrido que reflejaba la forma en cual se entendía la modernidad7. Para Steven Bunker, quien estudió el Palacio de Hierro en la Ciudad de México, es necesario profundizar en cómo las tradiciones locales influyeron en el desarrollo de las grandes tiendas y nuevos hábitos de consumo ${ }^{8}$. Si la historiografía sobre consumo ha destacado los aspectos trasnacionales del capital retail y la globalización de las redes y prácticas de consumo, resulta fundamental indagar cómo estos aspectos también influyeron sobre las experiencias e identidades de los trabajadores. La historiografía trasnacional ha demostrado que es necesario comprender la historia más allá de los límites del estado nación, sobre todo a partir de los flujos de capital, personas, tecnologías, e ideas. Con respecto al mundo del trabajo, Marcel van der Linden nos recuerda la necesidad no solo

4 MILLER, The Bon Marché.

5 LESSLIER, Claudie, “Employeés de grands magazins à Paris (avant 1914)”, Le mouvement social, núm. 105, octubre-diciembre 1978, pp. 109-126; BENSON, Susan Porter, Counter Cultures: Saleswomen, Managers, and Customers in American Department Stores, 1890-1940, Urbana, University of Illinois Press, 1986; QUEIROLO, Graciela Amalia, "Vendedoras: género y trabajo en el sector comercial (Buenos Aires, 1910-1950)", Revista Estudos Feministas, vol. 22, núm. 1, 2014, pp. 29-50.

${ }^{6}$ LANCASTER, The Department Store, pp. 125-158.

7 REYNOLDS, Nancy, A City Consumed: Urban Commerce, the Cairo Fire, and the Politics of Decolonization in Egypt, Stanford, Stanford University Press, 2012.

8 BUNKER, Steven, Creating Mexican Consumer Culture. 
de situar los procesos locales en un contexto más amplio sino también superar metodologías e interpretación eurocéntricas9. En otras palabras, señala Leon Fink, los procesos globales son "fundamentales para la historia del mundo del trabajo"10. De esta forma, la historiografía sobre América Latina ha estudiado como las empresas extranjeras importaron nuevas formas de organización de la mano de obra, el impacto de los organismos y redes internacionales sobre la regulación de las condiciones de trabajo, la influencia de movimientos globales como el anarquismo, la constitución de espacios fronterizos, y las estrategias de movimientos sociales y laborales de trascender los espacios locales y nacionales ${ }^{11}$. Finalmente, a modo de balance, en la historiografía chilena, ha prevalecido un cierto descuido por el enfoque trasnacional y la investigación del mundo del trabajo a mediados del siglo XX. Cabe precisar que los trabajadores del comercio no han sido objeto de estudio, por lo tanto, no se ha profundizado en sus experiencias y conflictos ${ }^{12}$.

A partir de estos debates historiográficos, nos planteamos el desafío de desentrañar la compleja intersección entre la construcción de espacios modernos de consumo y lugares de trabajo a través de la experiencia de Gath y Chaves en Chile entre 1910 y el cierre definitivo de la tienda en 1952. Gath y Chaves llegó a contar con cerca de 600 trabajadores entre vendedores, costureras, repartidores, y cocineros. Organizados en

9 LINDEN, Marcel Van Der, Workers of the World: Essays toward a Global Labor History, Leiden, Boston, Brill, 2008.

10 FINK, Leon, ed. Workers Across the Americas: The Transnational Turn in Labor History, Oxford, Oxford University Press, 2011.

${ }_{11}$ Para el caso de Chile cabe destacar los trabajos los diversos trabajos de Patricio Herrera sobre la Confederación Trabajadores de América Latina y su influencia en distintos movimientos obreros en América Latina, los estudios sobre la OIT de Juan Carlos Yáñez. Existe además una serie de investigaciones sobre solidaridad internacional y movimiento obrero durante dictadura.

12 En América Latina, diversos estudios han demostrado la importancia de estudiar a los empleados como un grupo con una identidad propia anclada en las experiencias de trabajo e ideas de clase y estatus social. La legislación social, en lugares como Chile y Perú, diferenció entre empleados y obreros, creando dos sistemas paralelos de organización sindical y derechos laborales. Estas diferencias no impidieron la construcción de alianzas políticas y sindicales. En la historiografía chilena de la última década, han emergido investigaciones sobre los orígenes de la legislación social y los empleados del Estado, pero es aún tema muy poco investigado. Para Chile, véase por ejemplo: BARR-MELEJ, Patrick, Reforming Chile: Cultural Politics, Nationalism, and the Rise of the Middle Class, Chapel Hill: University of North Carolina Press, 2001; CANDINA, Azun, Clase media, Estado y sacrificio: La Agrupación Nacional de Empleados Fiscales en Chile contemporáneo (1943-1983), Santiago, Lom Ediciones, 2013; SILVA, J. Pablo, "The Origins of White-Collar Privilege in Chile: Arturo Alessandri, Law 6020, and the Pursuit of a Corporatist Consensus, 1933-1938," Labor 3, no. 1 (2006): 87-112. 
dos sindicatos, los trabajadores participaron en la vida urbana local y en eventos políticos, asambleas, y mítines, mientras discutían los grandes temas nacionales que los afectaban ya fuese la inflación, los límites de la legislación social, o la inseguridad laboral. Al igual que en otras grandes empresas y centros industriales de la época, los beneficios y políticas empresariales y el origen extranjero del capital marcaron profundamente las relaciones de trabajo e, incluso, la organización del tiempo libre. Los equipos deportivos, las fiestas de fin de año, y la entrega de uniformes entre otros beneficios crearon una estrecha relación entre la empresa inglesa y los trabajadores. Sin embargo, si por un lado las prácticas paternalistas contribuyeron a formar una identidad particular anclada en el sentido de pertenencia a la casa comercial, el conflicto social también marcó las relaciones entre Gath y Chaves y los trabajadores sindicalizados. La huelga final de 1951-52 nos muestra el quiebre del modelo paternalista y la importancia histórica del movimiento sindical y sus vínculos políticos, tanto a nivel nacional como internacional.

Este artículo se sostiene fundamentalmente en información de prensa y fuentes impresas, las cuales nos permitieron reconstruir el desenvolvimiento de la casa comercial en Chile y el desarrollo del movimiento sindical. Se utilizó una gran variedad documental, fuentes tanto inglesas como sudamericanas, que nos permitieron profundizar en la visión de la casa comercial, también, en las experiencias de los trabajadores. La prensa, de diversas tendencias políticas, así como sindical, nos permitió reconstruir esta historia. A partir de la información que aparecía regularmente en el periódico británico The Times, la primera parte del artículo analiza el establecimiento de la casa comercial primero en Argentina y, posteriormente, en Chile. Publicaciones sindicales, revistas, y referencias bibliográficas nos permitieron reconstruir los grandes rasgos del mundo del trabajo. Entre estas fuentes, se utilizó el periódico de los trabajadores de Gath y Chaves en los años veinte. En la última sección, sobre la base de diarios chilenos y argentinos, se reconstruye el conflicto final, cierre de la tienda y vínculos trasnacionales. Específicamente, se utilizaron diarios chilenos de distintas tendencias políticas, derecha e izquierda, como $\mathrm{El}$ Mercurio y Las Noticias de Última Hora, respectivamente. Junto a ello, sesiones parlamentarias y, por último, la revista más importante de los empleados particulares de la época, denominada Los Empleados de Chile. Por otro lado, se utilizaron diarios 
argentinos como Democracia y El Laborista, los cuales informaron sobre los sucesos en Chile y las acciones de solidaridad.

\section{La historia de Gath y Chaves: de tienda familiar a empresa global}

Durante las primeras décadas del siglo XX, Gath y Chaves se convirtió en una de las cadenas de grandes almacenes más importantes de Argentina y Chile. Su transformación desde una empresa familiar a una gran tienda controlada por capitales británicos refleja los cambios en el negocio del retail a nivel global. Los orígenes de esta cadena comercial se remontan a 1883, año en que Alfredo Gath y Lorenzo Chaves inauguraron su primer local en la ciudad de Buenos Aires. El despliegue de mercaderías en sus vitrinas y su esfuerzo por atraer consumidores reflejaban la transformación del comercio y los hábitos de consumo de la población bonaerense. En 1908, el local se convirtió en Gath y Chaves Sociedad Anónima. Sus negocios e influencia prosperaron rápidamente, lo cual se refleja en la espectacular expansión de sus instalaciones en Buenos Aires y la inauguración de nuevas tiendas en ciudades de provincia. Entre 1895 y 1910, la mano de obra creció de solo 76 a 6.000 trabajadores y empleados ${ }^{13}$. En 1910, se inauguró el primer local en Santiago, Chile, convirtiéndose rápidamente en símbolo de la modernización que experimentaba la capital chilena. En mayo de 1912, Gath y Chaves S.A. fue adquirida por capitales británicos, pasando a llamarse The South American Store Gath y Chaves (o Almacenes Sudamericanos). Al momento de la compra, Gath y Chaves contaba con tres sucursales y tres fábricas en Buenos Aires, ocho tiendas en el resto de Argentina, y el local en Santiago, Chile. Para el periódico británico The Times, Gath y Chaves era:

"lejos el [negocio] más grande de su tipo en la República Argentina, similar a Bon Marché, Louvre, y Printemps en Paris, y a otras grandes tiendas en Londres y otros lugares que venden ropa, sombreros, textiles, perfumes, muebles, provisiones (...)”14.

La adquisición de Gath y Chaves por capitales británicos correspondía a una

${ }_{13}$ ROCCHI, Fernando, Chimneys in the Desert: Industrialization in Argentina during the Export Boom Years, 1870-1930, Stanford, Stanford University Press, 2006, p. 23.

14 The Times, Londres, 30 de mayo de 1912, p. 17, "New Capital Issues: The South American Stores (Gath and Chaves)". 
estrategia de las grandes cadenas comerciales de expandirse en las ciudades más importantes de América Latina, especialmente Buenos Aires, cuyo crecimiento demográfico ofrecía un atractivo mercado para el comercio detallista extranjero durante las primeras décadas del siglo XX ${ }^{15}$. En 1914, Harrods inauguraba un prestigioso local en la capital transandina, a sólo pocas cuadras de distancia de The South American Store, y, aunque sin mucho éxito, Bon Marché, la emblemática cadena francesa, también incursionó en el mercado porteño. El estallido de Primera Guerra Mundial reconfiguró las relaciones comerciales. Las dificultades de acceder a productos importados llevaron al cierre de Bon Marché en Buenos Aires. Otras tiendas se adaptaron a los cambios. En 1920, Harrods Buenos Aires y The South American Stores se fusionaron, consolidando el control británico del comercio retail en América del Sur ${ }^{16}$. De esta forma, entre 1883 y 1920, Gath y Chaves pasó de ser una empresa familiar argentina a ser una empresa global con redes comerciales que se extendían desde Europa a América del Sur. Estas redes globales afectarían no solo el desenvolvimiento de los negocios sino también la vida de los trabajadores.

En los años siguientes, la fusión de Harrods-Gath y Chaves posibilitó distribuir stocks de mercadería en forma más eficiente, mantener menos bodegas, y agilizar la circulación de productos tanto importados como locales. Harrods Buenos Aires reforzó su identidad de tienda exclusiva que vendía "productos de primera clase" a un público de élite. Por su parte, The South American Stores Gath y Chaves, con sedes en Argentina y Chile, buscó llegar a un público de clase media, expandirse en el mercado de provincia, y “cultivar el comercio de buena calidad”. Al igual que otros establecimientos comerciales, Gath y Chaves vendía tanto productos importados como locales y distribuía su propia marca, estableciendo una serie de redes comerciales a nivel local y regional. La importancia del abastecimiento local creció a medida que las condiciones del mercado, los impuestos de aduana, y los conflictos internacionales dificultaron y encarecieron la llegada de productos europeos. En 1929, por ejemplo, Sir Woodman Burbidge, gerente de Harrods Buenos Aires en Londres, explicaba que:

15 ROCCHI, Chimneys in the Desert, pp. 60-61.

16 The Times, Londres, 16 de febrero de 1920, p. 23, "The South American Stores (Gath \& Chaves), Limited". 
"una parte substancial de la mercadería que vendemos la compramos a través de nuestros agentes comerciales en Europa, mientas que prácticamente toda la ropa de hombres, mujeres y niños es confeccionada en nuestras fábricas en Argentina y Chile, y en estas fábricas empleamos alrededor de 2.000 trabajadores. Los altos derechos de aduana hacen más ventajoso confeccionar localmente"17.

Durante la década de 1930, el 70 por ciento de los productos que vendía Gath y Chaves era de origen nacional, productos que eran producidos directamente en sus fábricas y talleres o comprados localmente ${ }^{18}$.

Con un mercado considerablemente más pequeño, la expansión en Chile fue menos exitosa que en el país trasandino. En ese entonces, Santiago, una ciudad de cerca de 350.00o habitantes, experimentaba un rápido crecimiento demográfico y expansión territorial, pero era profundamente escindida y desigual ${ }^{19}$. Las posibilidades de consumo se restringían a la elite y a una pequeña clase media. El local en Santiago fue inaugurado en vísperas del centenario de la independencia. El edificio donde se instaló la tienda representaba la modernización del casco histórico de la ciudad que incluía, entre otras, las emblemáticas obras del Palacio de Bellas Artes (1913). Diseñado por el arquitecto Alberto Siegel Lübbe y el ingeniero Augusto Geiger a pedido del empresario Héctor Beeche, el edificio de Gath y Chaves contaba con los más recientes adelantos arquitectónicos. Su estructura de metal y concreto creaba grandes espacios abierto, mientras que los ascensores posibilitaban el movimiento vertical de los clientes ${ }^{20}$. Su edificio, vitrinas, publicidad, catálogos, y sistema de crédito representaban nuevas formas y prácticas de consumo, ofreciendo a la élite local una forma moderna de comprar y socializar $^{21}$. La tienda no solo era un espacio de compras, sino, sobre todo a partir de la inauguración del tea room en 1921, un espacio de socialización y encuentro en el centro

17 The Times, Londres, 10 de diciembre de 1929, p. 26, "Harrods (Buenos Aires), Ltd."

18 GRAVIL Roger, "British Retail Trade in Argentina, 1900-1940," The Inter-American Economic Affairs, vol. 24, núm. 2, 1970, pp. 3-26, p. 22.

19 De acuerdo a los censos, Santiago tenía 332.724 habitantes en 1907 y 507.00o en 1920. Sin embargo, Santiago era una ciudad segregada, en la cual la mayoría de la población vivía en la pobreza y en los barrios periféricos. DE RAMÓN, Armando, Santiago de Chile, Santiago, Editorial Sudamericana, 2000, pp. 184193.

${ }^{20}$ SALINAS, Ignacio, “Alberto Siegel Lubbe”, Auca, núm. 42, 1981, pp. 58-62.

${ }^{21}$ BARR-MELEJ, Reforming Chile, pp. 44-45; 
de la ciudad ${ }^{22}$. Gath y Chaves rápidamente se consolidó como la tienda más importante del país, compitiendo con las más antiguas Casa Pra y Casa Francesa ${ }^{23}$. En otras palabras, señalaba una reseña de los negocios británicos en Chile en 1919, "se contaba al fin con un establecimiento comercial elegante, fastuoso, europeo y, sobre todo, serio"24.

Gath y Chaves era uno de los establecimientos comerciales más importantes en Santiago; pero, desde una perspectiva global, los negocios en Chile siempre fueron marginales y, con la excepción de algunos años de prosperidad, parecieran estar siempre pasando por momentos difíciles. De acuerdo a las cuentas anuales a los socios de Harrods Buenos Aires que se publicaban regularmente en The Times, la sucursal chilena tuvo un desarrollo mediocre a comienzos de la década de 1920 e incluso de grandes pérdidas entre 1921-2425. A fines de los años veinte, las condiciones mejoraron. En 1928, Woodmand Burbidge y Paul Foucher visitaron las instalaciones en Santiago, y la tienda inició un proceso de modernización y expansión ${ }^{26}$. En los próximos años, se inauguraron varias sedes a lo largo del país incluyendo: Talca, Valdivia, Temuco, Valparaíso, y Concepción ${ }^{27}$. En diciembre de 1928, el periódico sindical describía con optimismo la renovación de las vitrinas, la llegada de nueva mercadería, y el aumento de las ventas ${ }^{28}$. Sin embargo, la Gran Depresión afectó nuevamente las ventas y en 1936 solo permanecían abiertas las sedes de Santiago, Valparaíso, y Concepción. Los años entre 1941-43 fueron nuevamente de auge y expansión de ventas, pero en los años siguientes las cuentas de socios prácticamente no mencionan los negocios chilenos. A fines de la década de 1940, South American Stores contaba con 8.300 empleados en Argentina y 600 en Chile. Estos ciclos económicos y la posición minoritaria de las inversiones en Chile afectarían las condiciones

\footnotetext{
${ }_{22}$ PEÑA MUÑOZ, Manuel, Los primeros cafés del siglo XX, Santiago, Ril editores, 2001, pp. 112-119.

23 DUSSAILLANT, Las reinas de Estado, p. 73.

24 El progreso británico en Chile, Santiago, Escobar y Baya Editores, 1919, pp. 60-61.

25 La cuenta a los socios de Harrods Buenos Aires era publicada regularmente en The Times en el mes de diciembre. Las referencias a Chile son siempre escuetas y no incluyen más que unas pocas frases. Esto contrasta con las referencias a la situación en Argentina.

${ }_{26}$ Boletín oficial de la U.I.O. de Gath y Chaves, Santiago, noviembre de 1928, pp. 4-5, "Los srs. Woodman Burbidge y Paul Foucher nos visitan”.

27 Prácticamente no existen referencia a estas sedes de provincial. La sede de Talca fue inaugurada en 1928 y cerrada definitivamente en 1932, la sede de Valdivia fue inaugurada en 1930, la sede de Temuco fue clausurada en abril de 1936.

${ }_{28}$ Boletín oficial de la U.I.O. de Gath y Chaves, Santiago, diciembre de 1928, pp. 5 y 8, "Renovación y elegancia”.
} 
de trabajo y la estabilidad laboral.

\section{El mundo del trabajo}

$\mathrm{Al}$ igual que otras grandes tiendas, Gath y Chaves requería de una abundante mano de obra de distintas calificaciones, trabajadores y empleados quienes se distribuían en departamentos, secciones, y pisos. Detrás de los vendedores, la cara más emblemática de la tienda, se escondía un amplio y diverso grupo de costureras, lavanderas, planchadoras, carpinteros, repartidores, y cocineros. Una suerte de microcosmo de la vida urbana, el edificio -coloquialmente llamado la casa-reproducía con precisión las diferencias ocupacionales tanto en el espacio físico (distribución de la fuerza de trabajo en los distintos pisos de la tienda) como en las características y condiciones de trabajo. A su vez las distintas ocupaciones reflejaban diferencias sociales o de estatus y de género, creando una mano de obra segmentada e identidades laborales propias ${ }^{29}$. La diferencia más importante se daba entre los empleados (a mensual) y los llamados trabajadores a jornal u obreros, lo cual se manifestaría en las distinciones legales establecidas por las leyes laborales a partir de 1924 .

Las divisiones dentro de la mano de obra se exhibían también en su distribución en el espacio físico. Por ejemplo, en el subterráneo estaba la carpintería y sección marcas, mientras que los talleres de las costureras y los sastres y las secciones de lavado, planchado, y envases se ubicaban en el último piso (quinto). En el cuarto piso estaba el tea room, la pastelería, y la peluquería. Las y los vendedores se dividían en múltiples secciones como lencería, guantes y pañuelos, juguetería, corbatería, o sport. En 1919, por ejemplo, la tienda ya contaba con 32 departamentos o secciones especializadas en la venta de distintos productos, los cuales con el tiempo iban siendo reorganizados de acuerdo a los cambios comerciales y la moda ${ }^{30}$.

$\mathrm{Al}$ igual que en otros establecimientos comerciales, la presencia de la mujer fue un

29 Llama la atención que el gran supermercado del siglo XXI reproduce este tipo de segmentación y diferenciación de la mano de obra. STECHER, Antonio; GODOY, Lorena; TORO, Juan Pablo, "Condiciones y experiencias de trabajo en la sala de venta de un supermercado. Explorando los procesos de flexibilización laboral en el sector del retail en Chile", Polis, vol. 9, núm. 27, 2019, pp. 523-550.

${ }^{30}$ El comercio británico en Chile, Santiago, Escobar y Blaya Editores, 1919, pp. 60-61. 
elemento fundamental del mundo del trabajo en Gath y Chaves. Desde comienzos del siglo XX, señala la historiadora Elizabeth Hutchison, las vendedoras pasaron a ser "un elemento fijo del paisaje urbano"31. F. Santiván, en un artículo publicado por en Pacifico Magazine en 1913, señalaba que las empleadas del comercio eran una nueva categoría social, "educadas en un liceo, gustan de la vida sociable, sienten la necesidad de vestir con corrección, han leído algunos libros y tienen sus aspiraciones más o menos elevadas" 32 . El trabajo de empleada, continúa Santiván, tenía sus sacrificios, pero también sus beneficios incluyendo la comisión por ventas que era habitual en las grandes casas comerciales, vacaciones, y bonos de navidad. Aunque las vendedoras eran la cara más emblemática del comercio, las obreras de los talleres de costura, lavado, y planchado también contribuían al funcionamiento de los grandes almacenes.

El taller continúa siendo uno de los aspectos menos conocidos del desarrollo de las grandes tiendas. Por ejemplo, en 1910, la revista Zig-Zag se refería a la Casa Francesa, junto a Gath y Chávez una de las grandes tiendas más importantes del país, como "un establecimiento comercial e industrial”. La Casa Francesa, con sucursales en Santiago y Valparaíso, habría introducido la venta de ropa hecha, la cual era fabricada en sus talleres donde "emplean centenares de operarios y obreras para abastecer sus almacenes", convirtiéndola en "un centro industrial de los mas importantes" 33 . Estos productos fabricados localmente eran vendidos junto con los artículos importados. De acuerdo a la información recopilada, el sistema de Gath y Chaves era similar, distinguiéndose sobre todo por la integración de los talleres en el mismo edificio de la venta. En Buenos Aires, por ejemplo, mantenía una compleja red de fábricas y talleres de confección e incluso desarrolló la modalidad de trabajo a domicilio para externalizar la producción y reducir $\operatorname{costos}^{34}$.

Desde sus inicios Gath y Chaves implementó un modelo de organización de la mano de obra con elementos paternalistas para aumentar la productividad y eficiencia,

${ }^{31}$ HUTCHISON, Elizabeth Quay, Labors Appropriate to Their Sex: Gender, Labor, and Politics in Urban Chile, 1900-1930, Durham, Duke University Press, 2001, p. 183.

32 Pacífico Magazine, Santiago, marzo de 1913, pp. 385-395, "La mujer que trabaja” por F. Santiván.

33 Zig-Zag, Santiago, s/n, 17 de diciembre de 1910, "Casa Francesa".

34 GUY, "Producción, ventas, y consumo". 
fortalecer el vínculo entre trabajadores y capital, y controlar el conflicto social35. En una época en la cual el paternalismo era uno de los elementos centrales en los grandes establecimientos industriales, Gath y Chaves también entregaba una serie de beneficios sociales que iban más allá del mundo del trabajo tales como la organización de eventos deportivos, la construcción del estadio, patrocinio de fiestas sociales y otras actividades recreativas (picnics, paseos), y entrega de mercaderías y productos. Si en los centros mineros e industriales, los programas de bienestar buscaban retener la mano de obra y consolidar la familia obrera como base de la estabilidad laboral, las casas comerciales enfatizaban el vínculo armónico entre empresa y empleados con miras a eliminar el conflicto social. Por ejemplo, Gath y Chaves se esforzó por crear una cierta "identidad" de empresa, lo que se reflejaba en el uso de uniformes de los repartidores y en un discurso público que resaltaba la imagen de "La Casa" como una gran familia. Los largos años de servicio eran ampliamente reconocidos, sugiriendo que existía una cierta estabilidad de la mano de obra. Las cuentas anuales de Harrods Buenos Aires en Londres terminaban siempre con un fraterno agradecimiento a sus más de 10.000 trabajadores en Sudamérica.

Las visitas de los gerentes extranjeros se convertían en un evento de repercusiones nacionales, donde dirigentes sindicales, autoridades políticas y gerentes compartían en almuerzos, inauguraciones, y actos celebratorios. Este fue el caso de la visita de Woodmand Burbidge y Paul Foucher en 1928. El viaje a Sudamérica duró casi 3 meses, Burbidge, quien viajó directamente de Londres, y Foucher (gerente de South American Stores en Buenos Aires) visitaron todas las sucursales argentinas (un total de 16). En Mendoza, tomaron el ferrocarril trasandino con destino a Chile. Al llegar a la estación de ferrocarriles en Santiago (Estación Mapocho), los esperaba una concurrida comitiva que incluía al gerente de la casa en Santiago, los jefes de las distintas secciones, y representantes del sindicato. En los días posteriores, el sindicato se reunió con Beveridge

35 La historiografía sobre paternalismo industrial ha demostrado la influencia y extensión de los programas de bienestar. En Chile, se ha estudiado fundamentalmente el mundo minero e industrial. El caso de Gath y Chaves levanta nuevas preguntas sobre la extensión del modelo al mundo comercial y urbano. Véase, por ejemplo, VIDELA Bravo, Enzo, Hernán VENEGAS VALDEBENITO, y Milton GODOY ORELLANA, El orden fabril. Paternalismo industrial en la minería chilena. 1900-1950, Valparaíso, América en Movimiento, 2016. 
para solicitarle apoyo para obras de mutualidad y actos deportivos. El día de la partida, un grupo de operarias ofreció "dos hermosos ramos de rosas y violetas atados de anchas cintas con los colores nacionales que correspondían a los visitantes (...) desde la plataforma enviaban besos los viajeros" 36 .

A pesar de estas iniciativas y programas, los conflictos eran frecuentes, enfocándose en las demandas clásicas de los trabajadores urbanos y del comercio. Así como en otras empresas, las políticas de bienestar marcaban la identidad de los trabajadores y, muchas veces, creaban vínculos de dependencia; pero, no eliminaban el conflicto37. Tanto para obreros como empleados, las demandas principales eran de carácter económico/salariales y la duración de la jornada de trabajo (la jornada de 8 horas y el llamado sábado ingles) ${ }^{38}$. Los trabajadores de Gath y Chaves eran partícipes de una sociedad urbana en ebullición, donde las reivindicaciones por el mejoramiento de las condiciones de trabajo se insertaban en un amplio movimiento social y eran parte de un proceso de construcción de una nueva institucionalidad laboral que buscaba regular las relaciones entre capital y trabajo. En este ambiente, la organización sindical no fue ajena al mundo del trabajo de Gath y Chaves. En 1925, los obreros fundaron la Unión Industrial de Operarios de Gath y Chaves. El sindicato contaba con cerca de 300 socios. Las obreras de los talleres tuvieron un rol preponderante en el sindicato, a tal punto que incluso en 1926 criticaban la poca adhesión y compromiso del "personal masculino" que contrastaba con el sacrificio de las compañeras obreras, quienes no solo asistían a las reuniones ni pagaban las cuotas. En el diario del sindicato, las obreras llamaban a los compañeros "No se Ud.; no sea cobarde; ni afocado [sic]; ni tímido; los espíritus débiles son la ruina de las organizaciones, de la familia y de la sociedad"39.

Siguiendo la antigua tradición mutualista, el sindicato entregaba una serie de

${ }_{36}^{6}$ Boletín oficial de la U.I.O. de Gath y Chaves, Santiago, noviembre de 1928, pp. 4-5, "Los srs. Woodman Burbidge y Paul Fouche nos visitan".

37 La compleja relación entre trabajadores y empresas en un modelo paternalista, lo hemos analizado en otras publicaciones. Véase: VERGARA, Ángela, "Paternalismo industrial, empresa extranjera y campamentos mineros en América Latina: un esfuerzo de historia laboral y transnacional”, Avances del Cesor (Rosario, Argentina) 10, no. 10 (2013): 113-128.

${ }_{38}^{8}$ El Sindicalista, Santiago, 1 de septiembre de 1935.

39 Boletín oficial de la U.I.O. de Gath y Chaves, Santiago, abril 8 de 1926, p. 5, "Para los que no asisten". 
beneficios a sus miembros (bono de enfermedad y bono en caso de muerte) y organizaba actividades sociales (equipo de baloncesto masculino y femenino, box, bailes sociales y publicación de un periódico). Las demandas económicas también eran importantes. El 17 de mayo de 1926, se convocó a un paro por demandas salariales (entre un 4 y un 20 por ciento dependiendo de la escala), el paro fue exitoso y ampliamente apoyado por la casi totalidad de los miembros del sindicato (quienes no apoyaron el paro fueron expulsados del sindicato). Hacia 1928, el sindicato señalaba, los obreros de la casa contaban con: semana corrida, 1 semana de vacaciones, ayudas en caso de muerte de familiar, asignación mortuoria (muerte del trabajador), sábado inglés (semana de 44 horas), apoyo material al sindicato, y reajustes salariales ${ }^{40}$. Respondiendo a cambios en la legislación laboral, en 1935, se refundó y pasó a llamarse Sindicato Industrial Gath y Chaves, el cual contaba con reconocimiento legal.

A diferencia de los obreros, los esfuerzos organizativos de los empleados fueron más lentos. Se tiene constancia de una unión de empleados a mediados de la década de 1920, la cual además se relaciona con las actividades de los empleados del comercio en Santiago. En 1924, se organizó la Unión de Empleados de Chile, la cual luchaba por la aplicación y extensión de la legislación social para los empleados particulares, y los empleados de Gath y Chaves participaron en algunas de sus convocatorias y marchas. En 1930, se fundó el Sindicato Profesional de Empleados (reconocido legalmente en 1933), con 314 miembros y una directiva integrada por cuatro hombres (presidente, secretario y dos directores) y una mujer (tesorera) ${ }^{41}$. Se requiere mayor investigación para conocer cómo se fue desarrollando el movimiento sindical a lo largo del tiempo y los vínculos entre empleados del comercio y personal obrero de los talleres 42 . Los sindicatos legalmente reconocidos, tanto de obreros como de empleados, presentaban pliegos de peticiones y negociaban regularmente con la empresa las condiciones económicas y de trabajo. Al igual que otros

40 Boletín oficial de la U.I.O. de Gath y Chaves, Santiago, noviembre de 1928, pp. 6-9, "El Paseo Campestre del Sindicato de Gath y Chaves".

41 "Nómina de sindicatos industriales y profesionales." Archivo Nacional de la Administración del Estado (ARNAD), Dirección del Trabajo, 1933, volumen 476.

42 La reconstrucción detallada del conflicto sindical entre la década del 20 y el fin de la tienda está fuera del alcance de este artículo. Para ello, se requiere una revisión minuciosa de la documentación del archivo de la Dirección General del Trabajo. Al igual que en el caso de otros sindicatos chilenos, no se cuenta con archivos sindicales. 
sindicatos, mantenían una serie de vínculos políticos y relaciones directas con dirigentes y representantes del Congreso Nacional.

Este entramado sindical y político resultó clave para enfrentar el fin de la tienda a comienzos de la década de 1950. Frente a la reducción de personal y las amenazas de cierre definitivo, los trabajadores convocaron a una huelga ilegal que se extendió por casi un mes (22 de diciembre de 1951 a fines de enero de 1952). Con el apoyo de los partidos políticos, el movimiento nacional de empleados, las redes internacionales, y la fuerte solidaridad y legitimidad del sindicato, los trabajadores de Gath y Chaves no solo se enfrentaron al capital británico, sino que pusieron en evidencia los límites de la legislación laboral chilena.

\section{La huelga final en Gath y Chaves: de los aliados históricos a la solidaridad internacional}

En los albores de la década de 1950, la clase política atravesaba por una profunda crisis de legitimidad, también, la economía y el proceso de sustitución de importaciones otorgaban señales de agotamiento. El costo de la vida había subido más de un 20 por ciento en 1951, alzas que no eran compensadas mediante reajustes salariales 43 . No solo los asalariados se veían afectados por los ciclos inflacionarios, además la legislación laboral era incompleta al no garantizar la estabilidad laboral ni tampoco, en el caso de los obreros, un salario mínimo. En este complejo escenario nacional, el presidente de la República, Gabriel González Videla (1946-1952), impulsó la Ley de Defensa Permanente de la Democracia en 1948, conocida como la "Ley Maldita". Mediante esta ley, fue ilegalizado el Partido Comunista, pero también, fue la principal arma estatal de contención contra la resistencia en el mundo del trabajo. Era la época de la modalidad de dominación represiva y el desencadenamiento de la Guerra Fría44. Frente a la inflación crónica, la amenaza del desempleo, la falta de derechos sindicales y el autoritarismo, el

43 SALAZAR, Gabriel y PINTO, Julio, Historia contemporánea de Chile III. La economía: mercados, empresarios y trabajadores, Santiago, LOM Ediciones, 2002; SALAZAR, Gabriel, La enervante levedad histórica de la clase política civil (Chile, 1900-1973), Santiago, Penguin Random House Grupo Editorial, 2015.

44 MOULIÁN, Tomás, Fracturas. De Pedro Aguirre Cerda a Salvador Allende (1938-1973), Santiago, LOM Ediciones, 2006. 
mundo del trabajo confió en sus tradiciones de lucha, re-articulando espacios de unidad, así como de colaboración entre obreros, empleados y partidos políticos. A mediados del siglo XX, se reforzó la confianza en la organización y acción de los trabajadores, lo cual se reflejó en la emergencia de las confederaciones y agrupaciones más importantes de la época, tanto de empleados particulares como públicos. En el transcurso de los años cuarenta, se organizaron nacionalmente los trabajadores del Estado y del sector privado 45 .

En este escenario, los trabajadores de la Casa Gath y Chaves enfrentaban una compleja situación laboral. Entre 1950 y 1951, fueron despedidos 170 empleados y 120 obreros, lo cual implicó una disminución del personal en un 40 por ciento. Junto a ello, se eliminaron secciones de ventas, y la mercadería fue comprada en consignación. Estos reajustes al interior de la casa comercial reflejaban un cambio en el modelo de producción y venta de mercaderías. Por ejemplo, se fueron disminuyendo los talleres, ya que era más económico comprar productos hechos. Por otro lado, fue cerrada la sucursal de la casa inglesa en Valparaíso y se temía el mismo destino para la tienda en Concepción. Más aún, los trabajadores se enteraron mediante la prensa que el gobierno pretendía comprar el edificio de calle Huérfanos, donde se encontraba ubicada la casa comercial en Santiago. Para los empleados y obreros, todo indicaba el cierre de la tienda. Desde el punto de vista de la empresa, los negocios en Chile eran cada vez menos relevantes.

Los trabajadores temían entonces lo peor: que luego de más de tres décadas al servicio de ésta, no contarían con una justa indemnización, ni tampoco, con inamovilidad en sus empleos ${ }^{46}$. A pesar del discurso paternalista, la tienda no los protegería frente a los cambios económicos. Asimismo, la legislación laboral chilena, en temas del derecho del

\footnotetext{
45 Los empleados comienzan a organizarse en la década de 1910 y participaron en la Federación Obrera de Chile. En 1924, se formó la Unión de Empleados de Chile. Luego de un período de represión, las organizaciones de empleados buscaron re-articularse durante el Frente Popular, sin embargo, no lograron superar divisiones políticas y gremiales. La principal organización de los trabajadores del Estado, denominada Agrupación Nacional de Empleados Fiscales (ANEF), se fundó en 1943. En 1948, el movimiento de empleado se reunifica y funda la Confederación de Empleados Particulares (CEPCH), la cual jugaría un papel importante en la reunificación del movimiento sindical a nivel nacional. BARRÍA, Jorge, El movimiento obrero en Chile, Santiago, Universidad Técnica del Estado, 1971.

${ }^{46}$ Las Noticias de Última Hora, Santiago, 21 de diciembre de 1951, p. 8, "Personal de Gath y Chaves acusa: la firma se lleva los capitales de Chile y pretende burlar a los empleados”.
} 
trabajo, inamovilidad y despido era incompleta y discriminaba contra los obreros. Mientras los empleados tenían derecho a una indemnización equivalente a un mes por año de servicio, el personal obrero solo tenía derecho a la irrisoria suma equivalente al sueldo de una semana de trabajo. En consideración de esta alarmante situación, en agosto de 1951, los trabajadores hablaron con la gerencia y, el 4 de diciembre, presentaron un pliego de peticiones. Al mismo tiempo crearon un comando único que representaba a todo el personal de la casa comercial, tanto obreros como empleados. Las demandas contenidas en el pliego eran básicas: garantía de estabilidad laboral e indemnización de un mes por año de trabajo en caso de despido o cierre de la tienda. No fueron escuchados.

La incertidumbre, el desamparo, y la inestabilidad laboral fueron los motivos principales de los trabajadores para presentar el pliego de peticiones. Ante la falta de consideración en torno a estas peticiones, los trabajadores creyeron vulnerados sus derechos y recurrieron a la Dirección General del Trabajo. Siguiendo el camino establecido por el Código del Trabajo, la Junta de Conciliación y Arbitraje evaluó las circunstancias legales del pliego. El día 19 de diciembre de 1951, la Junta convocó a los abogados de las partes en desacuerdo. Sin embargo, el representante de Gath y Chaves argumentó que los trabajadores sustentaban un conflicto ficticio. Esto fue rebatido por el abogado de éstos, quien subrayó la preocupación en torno a los despidos, la desprotección en que estaba el personal obrero, y el próximo cierre de la casa comercial. La Junta de Conciliación, finalmente decidió archivar el pliego, en base al argumento del abogado de la casa comercial inglesa, quien aseguró que no habría más despidos. Con ello, se cerraban varios caminos legales incluyendo el proceso de conciliación y la posibilidad de convocar a una huelga legal. La decisión de los funcionarios del trabajo, denunció el personal de la casa, "ha cerrado a los asalariados, sin ningún fundamento legal alguno, el camino pacífico y de orden" 47 .

Ante el fallo adverso de la Junta de Conciliación, los trabajadores confiaron en su propia unidad y organización, recurriendo a la estrategia sindical histórica ante el desentendimiento de los patrones y la falta de compromiso real de la institucionalidad

${ }_{47}$ El Mercurio, Santiago, 21 de diciembre de 1951, p. 11, "Lenidad de la Junta de Conciliación provoca grave conflicto en Gath \& Chaves". 
laboral: la huelga. Como una muestra de descontento y de presión, paralizaron sus labores desde la noche del 19 de diciembre 272 empleados y 100 obreros de la casa comercial Gath y Chaves en Santiago 48 .

El conflicto en Gath y Chaves reflejaba la época adversa por la cual atravesaba el mundo del trabajo. En la década de 1950, el Estado chileno no se caracterizó por respaldar las demandas económicas y laborales de los trabajadores, tampoco, los conflictos sindicales. Era, en el fondo, un período de desamparo de lo sindical, en que la acción de los trabajadores era la mejor forma para enfrentar las adversidades económicas. En muchos casos, las Juntas de Conciliación y la Dirección del Trabajo negaban la legitimidad de las peticiones de los trabajadores, obligándolos a recurrir a acciones directas. Los vacíos jurídicos en materia de conflicto colectivo dejaban a los trabajadores y sus organizaciones desamparados y expuestos a una serie de sanciones legales 49 .

En el mismo momento en que emergía la huelga de los trabajadores de Gath y Chaves, los empleados particulares y públicos del país se movilizaban tanto por reajustes salariales como por la derogación de la Ley de Defensa Permanente de la Democracia y la modificación del Código del Trabajo. Ante la ebullición sindical de los trabajadores de "cuello y corbata", el gobierno no tardó en reaccionar. Decretó la reanudación de faenas en torno a una huelga en el Banco de Chile y estos trabajadores fueron perseguidos, bajo la denuncia de infracción a la Ley de Defensa de la Democracia5o.

La huelga de los trabajadores de Gath y Chaves fue realizada en un momento decisivo para la casa comercial. En pleno período navideño, el conflicto quebrantó el orden de la ciudad, el desenvolvimiento habitual de su vida comercial, y las prácticas de consumo de sus ciudadanos. En respuesta, la gerencia denunció la inconfesable intención de los trabajadores y sus motivos políticos, más aún, el vocero de los empresarios de Chile,

48 Las Noticias de Última Hora, Santiago, 20 de diciembre de 1951, "Comenzó huelga de empleados en Casa Gath y Chaves, hoy", p. 24.

49 CAMU VELOSO, Arnoldo, Estudio crítico de la huelga en Chile, Santiago, Editorial Jurídica, 1964.

${ }^{50}$ Las Noticias de Última Hora, Santiago, 29 de diciembre de 1951, "Los empleados del Banco de Chile mantendrán sus peticiones, porque dicen son de estricta justicia", p. 16. ; Las Noticias de Última Hora, Santiago, 4 de enero de 1952, "Los políticos propusieron el arbitraje a los bancarios: un día de largos e intensos trajines", p. 4. 
aseguró que era necesario reprimir el conflicto. En una declaración publicada en $E l$ Mercurio, la gerencia de la casa comercial indicó

"Es muy sugerente el momento escogido para declarar la huelga ficticia e ilegal. Hace un mes que se anunció por la prensa el proyecto de compra del predio de la calle Estado y Huérfanos. Pero se aguardó para producir la paralización del trabajo, que llegaran los días inmediatos a la Pascua, en que, como es sabido, realizan los establecimientos de esta índole el gran volumen de sus ventas. Queda así en evidencia el espíritu que anima a los promotores del conflicto" ${ }^{1}$.

Sin embargo, el conflicto de Gath y Chaves presentó diversas particularidades que lo tornan sumamente interesante. Mientras los empleados en huelga del Banco de Chile eran perseguidos bajo la "Ley Maldita" y sus dirigentes detenidos, el gobierno tuvo una consideración especial con los trabajadores de Gath y Chaves, en respaldo de una militancia política en común, que demostró la lealtad del Partido Radical con sus asalariados. De hecho, el departamento sindical del Partido Radical los acompañó en las visitas ministeriales y realizó numerosas gestiones para solucionar el conflicto. A comienzos de diciembre, los trabajadores de Gath y Chaves y dirigentes del Partido Radical se reunieron con el ministro del Interior para darle a conocer su preocupación en torno a su empleo ${ }^{52}$. Por otro lado, inmediatamente tras el anuncio de la paralización, fue recibido el presidente del sindicato, dirigente Dionisio Rojas, de militancia radical. Para solucionar el conflicto, el presidente de la República instruyó a su ministro del Trabajo, Alejandro Serani (Partido Democrático), para que intercediera por los trabajadores ante la gerencia y el abogado de la Casa Gath y Chaves. De hecho, en enero, Serani reafirmó que el gobierno no abandonaría a los trabajadores y, en caso despido, se concedería a todo el personal la indemnización reclamada53. Al respecto, dijo:

"Las autoridades [...] no han abandonado a ese personal, pues fueron tomadas todas las medidas legales conducentes, e incluso el propio Presidente de la República, realizó gestiones directas ante la Gerencia de la firma para evitar el cierre. Además, para el caso de

${ }^{11}$ El Mercurio, Santiago, 22 de diciembre de 1951, p. 12, "Huelga ilegal y sin base”.

${ }^{2}$ Las Noticias de Última Hora, Santiago, 5 de diciembre de 1951, p. 16, "Gath y Chaves cerrará sus puertas: sus empleados pidieron garantías".

53 El Mercurio, Santiago, 18 de enero de 1952, p. 19, "Min. Serani actúa en Gath y Chaves". 
que está medida fuera inevitable, se ha obtenido que la casa conceda una indemnización extraordinaria, aparte de la que le corresponde de acuerdo con las leyes vigentes" 54 .

Que el gobierno respaldara a los trabajadores y que no aplicara disposiciones restrictivas, no era frecuente en la década de 1950, especialmente teniendo en cuenta la modalidad de dominación represiva que caracterizó al gobierno de González Videla. La institucionalidad laboral vigente no solo no implicaba un resguardo estatal ante una huelga ilegal, sino que la criminalizaba. Todo indica que en este caso influyó el vínculo del Partido Radical con los trabajadores de Gath y Chaves. El Partido Radical no solo asistió con los dirigentes sindicales a las reuniones ministeriales, sino que tornó visible la aflictiva situación de los empleados y obreros de Gath y Chaves55. Desde el Congreso Nacional, el senador radical Isauro Torres denunció a la casa comercial inglesa de atropellar los derechos de los trabajadores y de no haber concedido aumentos salariales o gratificaciones. Torres no solo reivindicó que las demandas de los asalariados eran justas, sino que además exponía los abusos de una casa comercial que se jactaba de ser una "gran familia" 56 . La izquierda, agrupada en el Frente del Pueblo, también expresó su solidaridad con los trabajadores en huelga, exigiendo "una solución pronta y satisfactoria a las huelgas reivindicativas del personal del Banco de Chile y de la empresa Gath y Chaves" 57 . De este modo, los dirigentes sindicales y políticos llevaron un conflicto corporativo del mundo del trabajo al debate político nacional, transformándolo en una preocupación del presidente de la República.

En una época en la cual el movimiento sindical chileno recobraba una inusitada confianza en su propia capacidad de presión y de resolución de sus demandas, los trabajadores en huelga recibieron el apoyo de la Confederación de Empleados

54 El Mercurio, Santiago, 25 de enero de 1952, p. 23, "EE. de Gath y Chaves en B. Aires ignoran legislación chilena".

55 Los Empleados de Chile, Santiago, 25 de enero de 1952, "La situación del personal de Gath y Chaves es discutida en la Cámara de Senadores", pp. 19 y 27.

${ }^{56} \mathrm{El}$ diputado radical Isauro Torres destacó: "Los empleados y obreros de Gath y Chaves se han sacrificado año tras año a favor de esa empresa, para que la firma obtenga pingües utilidades de que ha disfrutado. Lógico y humano es, ahora, defender a ese personal y sus familias". En: "Situación del personal de la Casa Gath y Chaves - oficio”, Cámara de Senadores, sesión 17.a extraordinaria, 8 de enero de 1952, p. 699.

57 Las Noticias de Última Hora, Santiago, 4 de enero de 1952, "Rechazar medidas de violencia contra el movimiento de Empleados Particulares acordó Frente del Pueblo”, p. 3. 
Particulares de Chile (CEPCH). La CEPCH, desde su creación en el año 1948, buscó representar nacionalmente las demandas de estos trabajadores y sus conflictos. Con esta convicción, respaldó inmediatamente a los trabajadores de Gath y Chaves, también, del Banco de Chile. Desde fines de diciembre de 1951, en consideración del notable malestar sindical, comenzó a debatir en torno a la idea de convocar a un paro nacional en solidaridad con estos conflictos $5^{8}$. Para ello, se convocaron múltiples asambleas. Pese a la modalidad de dominación represiva, los empleados no mostraron temor. La experiencia les indicaba que las demandas salariales o laborales, eran tratadas como un problema policial, que se resolvía mediante la represión y violencia estatal. Sin embargo, no retrocedieron. El presidente de la $\mathrm{CEPCH}$, sindicalista radical Juan Atala, declaró en la prensa:

"No nos asustan las amenazas de ninguna especie. Estamos preparados para toda emergencia. No se olvide que desde ahora todos los empleados nos hemos constituido en dirigentes de los destinos del gremio y que los empleados en Chile suman más de ciento veinte mil"s9.

A comienzos de enero de 1952, la CEPCH convocó a un paro nacional indefinido, por una plataforma que contemplaba demandas solidarias, laborales, económicas y políticas. Se exigía también la solución del conflicto de los empleados de Gath y Chaves, así como del Banco de Chile; una ley de estabilidad laboral, aumento del sueldo vital; la derogación de la ley de defensa de la democracia, entre otros ${ }^{60}$. El llamado de los empleados particulares tuvo impacto inmediato en el mundo del trabajo, apareciendo tempranamente en la prensa muestras de adhesión sindical ${ }^{61}$. También, en esta coyuntura fue reivindicada la huelga como la principal estrategia de lucha de los trabajadores por parte de los líderes sindicales más importantes de la época ${ }^{62}$. Pese a la legitimidad de esta

${ }^{8}$ El Mercurio, Santiago, 25 de diciembre de 1951, p. 49, "Continuó cerrada la casa Gath y Chaves"; El Mercurio, Santiago, 31 de diciembre de 1951, p. 27, "Sin solución paros en Banco de Chile y Gath y Chaves". 59 Las Noticias de Última Hora, Santiago, 4 de enero de 1952, p. 6, "El paro de los empleados es por el incumplimiento de las promesas de 1950, declara el dirigente Atala”.

60 Ibíd.

${ }^{61}$ Los Empleados de Chile, Santiago, 25 de enero de 1952, p. 32, "Diversos problemas gremiales ha planteado la JUNECH a S.E.”.

${ }^{62}$ Las Noticias de Última Hora, Santiago, 5 de enero de 1952, p. 7, "Los trabajadores de la prensa apoyan huelgas de bancarios y EE. Particulares"; Las Noticias de Última Hora, Santiago, 6 de enero de 1952, p. 12, 
táctica, el llamado de la CEPCH perdió fuerza rápidamente. Tan solo los días 3 y 4 de enero, logró mayor adhesión este llamado, principalmente entre los trabajadores de industria y de comercio ${ }^{63}$. Sin embargo, el cierre de oportunidades para la acción sindical por la aplicación de la Ley de Defensa Permanente de la Democracia, tuvo efectos ${ }^{64}$. Específicamente, los empleados del Banco de Chile, el día 5 de enero de 1952, llegaron a un acuerdo con sus empleadores, por lo tanto, regresaron a sus labores y la represión estatal contra ellos se extinguión 65 .

En el transcurso de enero de 1952, la CEPCH continuó respaldando a los trabajadores de Gath y Chaves. Tras el paro nacional de comienzos de aquel mes, convocó a asambleas, así como a un mitin público el día 15, en la Plaza Bulnes de Santiago, para exigir la solución de este prolongado conflicto y denunciar la "intransigencia patronal y la indiferencia estatal"66. A nivel nacional, continuaron su lucha por reajustes salariales, la reforma del Código del Trabajo, y la derogación de la "Ley Maldita”67. En este clima de creciente descontento y movilización social, el ministro del Interior, Alfonso Quinteros, denunció que el país experimentaba una "agitación subversiva”, representando con ello no solo la preocupación del gobierno, sino que de la derecha política y económica ${ }^{68}$. Ante esto, los empleados respondieron: "No hay agitadores incipientes ni profesionales, no hay

\footnotetext{
"Dice Clotario Blest: renunciar al derecho de huelga significa la quiebra del movimiento gremial y la más flagrante de las traiciones".

${ }_{6}$ El Mercurio, Santiago, 3 de enero de 1952, p. 17 "Paro nacional e indefinido acordó Conf. De Empleados". ${ }^{6} 4$ El Mercurio, Santiago, 3 de enero de 1952, p. 17, "Los empleados bancarios en huelga ilegal se colocan en plano manifiestamente subversivo".

${ }^{6}$ El Mercurio, Santiago, 4 de enero de 1952, p. 13, "Empleados del Banco de Chile, en asamblea, conocerán proposición de avenimiento para reanudar sus labores"; El Mercurio, Santiago, 7 de enero de 1952, p. 19, "El Banco de Chile reanudará hoy su atención al público"; El Mercurio, Santiago, 8 de enero de 1952, p. 21 "Ministro concedió libertad bajo fianza a tres empleados del Banco de Chile"; El Mercurio, Santiago, 16 de enero de 1952, p. 27, "Cerrado proceso contra bancarios".

${ }^{66}$ Las Noticias de Última Hora, Santiago, 16 de enero de 1952, “Todos los empleados particulares seguirán en su batalla por un vital de 6.500 pesos; así lo acordaron ayer en un gran mitin”, p. 5 .

${ }_{67}$ Los Empleados de Chile, Santiago, 25 de enero de 1952, p. 43, "No hay agitación: hay problemas gremiales".

68 El Mercurio, Santiago, 2 de enero de 1952, p. 2, "Clima de agitación fomentan dirigentes de Confederación y Federaciones de Empleados"; El Mercurio, Santiago, 4 de enero de 1952, p. 3, "Extremos de una crisis"; El Mercurio, Santiago, 5 de enero de 1952, p. 3, "Ante la suprema amenaza".
} 
política, ni oficial ni de oposición. Hay problemas gremiales. Hay inquietud por el destino de los empleados particulares. Hay sinsabor de no ser escuchados"69.

A medida que el conflicto se alargaba, los trabajadores de Gath y Chaves contaron con la intermediación del gobierno de Gabriel González Videla, también, de la principal confederación de empleados en Chile. En todo ello, se demostró la importancia de los aliados históricos en la resolución del conflicto: un partido político de militancia en común. También, la trascendencia de la unidad de clase, así como de tradiciones de lucha sindical. Sin embargo, en la resolución final del conflicto, los empleados y obreros de la casa comercial inglesa, requirieron de la solidaridad sindical internacional para obtener un triunfo decisivo, para alcanzar íntegramente sus demandas. En Chile, la acción sindical aún no lograba, por sí misma, trazar un sendero por la tan anhelada justicia social.

Gath y Chaves era una empresa británica con inversiones en Chile y Argentina. Las noticias de la huelga involucraban no solo a gerentes y administradores en diferentes países, sino también a los trabajadores de los distintos establecimientos. El 23 de enero, Democracia de Buenos Aires informó que Gath y Chaves "iniciaría el remate de sus instalaciones y existencias, debido a la imposibilidad de llegar a un acuerdo con sus empleados"7o . A fines de enero, la Federación Obrera Nacional de la Industria del Vestido y Afines expresó su solidaridad con los trabajadores chilenos en huelga, ofreciendo apoyo moral y material. La federación convocó a una asamblea de todo el personal de Gath y Chaves en Buenos Aires, exigiendo a la empresa que los trabajadores chilenos

\footnotetext{
"sean beneficiados con medidas que contemplen las disposiciones de nuestra avanzada legislación social, debida a la obra de nuestro Presidente Perón y de su digna esposa, señora Eva Perón, que conforme a los postulados y doctrina de la Revolución Justicialista a cuyo impulso se forja la Nueva Argentina"71.
}

Como medida de solidaridad, la Federación del Comercio se reunió con el directorio

\footnotetext{
${ }^{69}$ Las Noticias de Última Hora, Santiago, 11 de enero de 1952, p. 6, "No hay agitación: hay problemas gremiales dicen los empleados al Ministro del Interior".

70 Democracia, Buenos Aires, 23 de enero de 1952, "Rematan una gran tienda en Chile: mas desempleo".

${ }^{71}$ El Laborista, Buenos Aires, 24 de enero de 1952, "Solidarízanse con los obreros chilenos empleados del Vestido y del Comercio de nuestro país".
} 
de Gath y Chaves en Buenos Aires, y declaró "en estado de asamblea a todo el personal de la firma hasta que finalice el pleito"72.

Durante los días finales del conflicto, los sindicatos peronistas enfatizaron dos aspectos. Por un lado, denunciaron el egoísmo de los accionistas británicos que "deja en la calle a cientos de trabajadores chilenos". Por otro lado, declaraba la Confederación de Empleados del Comercio, la "falta en ese país hermano de legislación obrera que ampare los derechos y apoye las legítimas aspiraciones de mejoramiento social y económico de los trabajadores". ${ }^{73}$ En términos más amplios el discurso y las expresiones de solidaridad de los sindicatos argentinos se insertaban en un esfuerzo por internacionalizar el Peronismo y, a través de actos de "fraternidad", expandir su influencia en América Latina ${ }^{74}$. En el caso de Gath y Chavés, los contactos se reforzaban por el carácter trasnacional de la empresa. El dirigente chileno, Marcial Contreras Sepúlveda, viajó directamente a Buenos Aires para solicitar el apoyo de los empleados de Gath y Chaves y de la Federación Nacional de la Industria del Vestido y Afines en dicha ciudad.

El acuerdo final en beneficio de los trabajadores de Gath y Chaves, emergió de las discusiones entre la gerencia sudamericana de la casa comercial con el ministro del Interior de Perón y secretario de la CGT, Ángel Borlenghi 75. Tal como concluía el encargado laboral de la embajada británica en Buenos Aires, W.M. Wylie, la intervención sindical argentina fue clave para resolver el conflicto a favor de los trabajadores chilenos, ya que "La empresa Gath y Chaves en Buenos Aires no tuvo más opción que aceptar la aplicación de la ley argentina de indemnización, sino habrían tenido que enfrentar problemas más serios en sus actividades en Argentina" ${ }^{76}$. En otras palabras, la casa comercial cedía en Chile para proteger su posición en Argentina. Es importante destacar

\footnotetext{
${ }^{2}$ Democracia, Buenos Aires, 25 de enero de 1952, "La CGT ratificó su apoyo a los trabajadores chilenos en conflicto".

73 Democracia, Buenos Aires, 24 de enero de 1952, "Obreros argentinos apoyan las justas demandas de trabajadores chilenos".

74 SEMÁN, Ernesto, Ambassadors of the Working Class: Argentina's International Labor Activists and Cold War Democracy in the Americas, Durham, Duke University Press, 2017.

75 The Times, Londres, 26 de enero de 1953, p. 3, "Dispute In British Owned Stores",

${ }^{76}$ W.M. Wylie, Labour Attaché's Office, British Embassy, Buenos Aires, 4 de 1952, The National Archives, Kew (Reino Unido), LAB $13-495$.
} 
que las inversiones en Chile eran mínimas al compararse con Argentina y durante varios períodos (comienzos de los años treinta y de los años cuarenta) la sucursal chilena había operado con pérdidas. Cuando a fines del mes de enero de 1952, la CGT amenaza extender el conflicto chileno a Argentina y tildaba a Gath y Chaves de "capitalistas anti-sociales con apetitos insaciables”, amenazaba los frágiles equilibrios que mantenía el capital británico durante la era peronista.

El 26 de enero de 1952, Dionisio Pinto, presidente del sindicato de trabajadores de Gath y Chaves, citó a sus compañeros en el local sindical de la CEPCH. Tras más de un mes de huelga y ante más de doscientos trabajadores y con la presencia de los dirigentes de la CGT Argentina, Pinto anunció el arreglo final. La solución corroboró el pago de una gratificación extraordinaria para todo el personal equivalente al sueldo de un mes por cada año de servicio (hasta un máximo de 23 años sobre la base del promedio del sueldo mínimo de los últimos cinco años)77. La indemnización extraordinaria se pagaría a todo el personal de la casa comercial entre 30 y 60 días y complementaba, en el caso de los empleados, la indemnización legal por años de servicio que entregaba la Caja de Empleados Particulares ${ }^{78}$. Esto representaba un gran logro sindical, pues se expandían los derechos establecidos en la legislación laboral chilena. Más aún, los obreros, no amparados legalmente en cuanto a la indemnización por años de servicios, obtenían las mismas conquistas que sus compañeros empleados. 79

Junto con anunciar el arreglo, el cual sería firmando el día 31 de enero, los organizadores agradecieron la solidaridad argentina. Dos delegados de la CGT viajaron especialmente a Chile, "Cuando usaron de la palabra los delegados argentinos", la prensa

77 El Mercurio, Santiago, 26 de enero de 1952, p. 13, "Acuerdo con EE. de firma Gath y Chaves"; Las Noticias de Última Hora, Santiago, 30 de enero de 1952, p. 3, "Ovacionados por empleados de Gath y Chaves dos personeros de la CGT, de Buenos Aires"; El Mercurio, Santiago, 27 de enero de 1952, p. 13, "Bases del arreglo en firma Gath y Chaves"; El Mercurio, Santiago, 1 de febrero de 1952, p. 11, "Firma de acuerdo en Casa Gath y Chaves".

${ }_{78}$ En 1952, señala Moisés Poblete Troncoso, la legislación vigente (Ley 6020 de 1937) garantizaba "una indemnización en favor del empleado que se deja sin trabajo, equivalente a un mes por año de servicios. Para pagar dicha indemnización se ha constituido un fondo formado por el 8,33\% del sueldo del empleado, que debe pagar el empresario". POBLETE TRONCOSO, Moisés, El derecho del trabajo y la seguridad social en Chile, Santiago, Editorial Jurídica, 1949, p. 168.

${ }^{79}$ El Mercurio, Santiago, 27 de enero de 1952, "Se revelan detalles del acuerdo con la firma Gath y Chaves", 13. 
informó, "la concurrencia les ovacionó, vivó al señor Perón, a la CGT, etc., entonando dos veces el himno patrio"8o. Desde la esperanza por un notable triunfo, los trabajadores de Gath y Chaves acordaron que con el pago de indemnización extraordinaria que recibirían, más un préstamo de la Caja de Empleados Particulares, comprarían las mercaderías de la casa comercial en Chile y formarían una cooperativa ${ }^{81}$. Estos sueños, ya serían parte de otra historia.

El conflicto fue solucionado. Sin embargo, en los próximos meses, Gath y Chaves cerró definitivamente sus puertas en Santiago, los trabajadores recibirían su indemnización e intentarían infructuosamente crear una cooperativa. El escritor y cronista chileno, Oreste Platt, dedica algunas de sus páginas de El Santiago que se fue a Gath y Chaves. Luego de describir la tienda y su renombrado salón de te (tea room), concluye, con un cierto aire de nostalgia, "y fue una víspera de Navidad de 1952, que el personal de Gath y Chaves estimó ir a una huelga, la que se sostuvo por semanas, lo que llevó a la empresa a bajar las cortinas metálicas definitivamente y cerrar la casa en Chile"82. El New York Times, en enero de 1952 informaba que "La gran tienda británica Gath y Chaves, la más grande Chile, anunció hoy que liquidaría todas sus operaciones por la imposibilidad de solucionar la huelga de un mes de sus 500 empleados". ${ }^{83}$ En 1952, Harrods Buenos Aires puso fin tanto al conflicto como a sus inversiones en Chile, adaptándose y resguardando sus intereses en Argentina, donde permanecería hasta 1974.

En los años siguientes, Gath y Chaves se volvería un mito: el glamour de la casa comercial, las tardes en el tea room, y los elegantes catálogos que ofrecían los más variados artículos de consumo. Sin embargo, detrás de los maniquíes existía un complejo mundo de relaciones laborales, donde convivían obreros y empleados, costureras y vendedoras. $\mathrm{Si}$, por un lado, al menos en las primeras décadas, la casa comercial desarrolló un ambicioso programa paternalista que buscaba fortalecer los lazos entre la

80 Las Noticias de Última Hora, Santiago, 30 de enero de 1952, p. 3, "Ovacionados por empleados de Gath y Chaves dos personeros de la CGT, de Buenos Aires".

${ }^{81}$ Las Noticias de Última Hora, Santiago, 10 de enero de 1952, p. 16, "La JUNECH pidió dinero al gobierno para transformar Gath y Chaves en cooperativa"; El Mercurio, Santiago, 2 de febrero de 1952, p. 17, "Personal propuso la compra de intereses de Gath y Chaves".

82 PLATT, Oreste, El Santiago que se fue: apuntes de la memoria, Santiago: Biblioteca Nacional, 1999, 199. 83 New York Times, Nueva York, 24 de enero de 1952, p. 13 
empresa y el personal y reducir los conflictos. Por otro lado, los trabajadores desarrollaron una identidad propia como asalariados que se fue manifestando en la pertenencia al sindicato, la solidaridad de clase, y la participación en la vida urbana y política. Cuando en 1951, los trabajadores se vieron frente a las maniobras de la empresa por reducir personal y a la estrategia legal de deslegitimizar sus peticiones, recurrieron a estos vínculos y prácticas aprendidas, recibiendo el apoyo de otras organizaciones sindicales, partidos políticos, e, incluso, de los sindicatos al otro lado de la cordillera. Aunque no lograron mantener sus empleos y las vitrinas se apagaron, obtuvieron un triunfo inédito que se convirtió en un preámbulo de la unidad entre obreros y empleados y las reformas a la legislación laboral que se introducirían en los próximos años.

\section{Conclusiones}

La historia de Gath y Chaves sugiere la importancia de vincular la historia del consumo a la historia de las y los trabajadores, el surgimiento de nuevas identidades laborales, la transformación de los espacios de trabajo, y la cada vez más compleja relación entre empresarios, trabajadores, y consumidores/ciudadanos. También nos sugiere la importancia de indagar más en la historia de los empleados del comercio, un tema poco estudiado por la historiografía chilena, y la relación entre empleados y obreros al interior de la casa comercial. Asimismo, esta historia trasciende los espacios nacionales. Los capitales británicos transformaron el comercio urbano tanto en Argentina como en Chile, expandiendo redes comerciales y nuevas formas de producción, distribución y ventas de artículos. Este escenario comercial marcó profundamente la vida de los trabajadores. Si, por un lado, Gath y Chaves implementó políticas de corte paternalista y transformó las formas tradicionales de trabajo en los establecimientos comerciales; por otro lado, el desenvolvimiento del local en Chile estuvo supeditado a los intereses globales de la empresa. Sin embargo, el carácter internacional de la empresa también creó oportunidades para fortalecer lazos de solidaridad sindical. Durante la huelga final de 1951-52, los trabajadores chilenos recibieron el apoyo de sus pares argentinos, transformando una huelga local en un conflicto que atravesó fronteras. Este caso, en su más alta complejidad, no había sido observado por la historiografía chilena. En términos más amplios. De esta forma, este artículo busca levantar nuevos temas que incorporen la 
diversas de formas de trabajo y sindicalización que superen un enfoque que se ha centrado exclusivamente en la experiencia obrera como así también un enfoque trasnacional en los conflictos locales de los asalariados.

$\diamond \diamond \diamond \diamond \diamond \diamond \diamond \diamond \diamond \diamond$

\section{Fuentes citadas}

Boletín oficial de la U.I.O. de Gath y Chaves, Santiago

Democracia, Buenos Aires

El comercio británico en Chile, Santiago, Escobar y Blaya Editores, 1919.

El Laborista, Buenos Aires

El Mercurio, Santiago

El Sindicalista, Santiago

Las Noticias de Última Hora, Santiago

Los Empleados de Chile, Santiago

Pacífico Magazine, Santiago,

The New York Times, EE.UU

The Times, Londres, UK

Zig-Zag, Santiago.

\section{Bibliografía citada}

BARR-MELEJ, Patrick, Reforming Chile: Cultural Politics, Nationalism, and the Rise of the Middle Class, Chapel Hill, University of North Carolina Press, 2001.

BARRÍA, Jorge, El movimiento obrero en Chile, Santiago, Universidad Técnica del Estado, 1971

BENSON, Susan Porter, Counter Cultures: Saleswomen, Managers, and Customers in American Department Stores, 1890-1940. Urbana, University of Illinois Press, 1988.

BUNKER, Steven, Creating Mexican Consumer Culture in the Age of Porfirio Díaz. Albuquerque, University of New Mexico Press, 2012.

CAMU VELOSO, Arnoldo, Estudio crítico de la huelga en Chile, Santiago, Editorial Jurídica, 1964. 
CANDINA, Azun, Clase media, Estado y sacrificio: la Agrupación Nacional de Empleados

Fiscales en Chile contemporáneo (1943-1983), Santiago, Lom Ediciones, 2013.

CROSSICK, Geoffrey; JAUMAIN, Serge, Cathedrals of Consumption: The European Department Store, 1850-1939, Brookfield, Ashgate.

DE RAMÓN, Armando, Santiago de Chile, 1541-1991: Historia De Una Sociedad Urbana, Santiago, Editorial Sudamericana, 2000.

DUSSAILLANT, Jacqueline, Las reinas de Estado: consumo, grandes tiendas y mujeres en la modernización del comercio de Santiago (1880 1930), Santiago, Ediciones Universidad Católica, 2011.

FINK, Leon, ed. Workers Across the Americas: The Transnational Turn in Labor History, Oxford, Oxford University Press, 2011.

GRAVIL Roger, "British Retail Trade in Argentina, 1900-1940," The Inter-American Economic Affairs, vol. 24, núm. 2, 1970, pp. 3-26,

GUY, Donna. "Producción, ventas y consumo: reflexiones sobre el papel del género en las tiendas grandes de Buenos Aires, 1883-1930", Descentrada 2, no. 1, 2018.

HUTCHISON, Elizabeth Q, Labors Appropriate to their Sex: Gender, Labor, and Politics in Urban Chile, 1900-1930, Durham, Duke University Press. 2001.

LANCASTER, William,The Department Store: A Social History, Londres, Leicester University Press, 1995.

LESSELIER, Claudie, "Employées de grands magasins à Paris (avant 1914)", Le Mouvement Social , no. 105, 1978, pp. 109-126.

LINDEN, Marcel Van Der, Workers of the World: Essays toward a Global Labor History, Leiden, Boston, Brill, 2008.

MILANESIO, Natalia, Cuando los trabajadores salieron de compras: nuevos consumidores, publicidad, y cambio cultural durante el primer peronismo, Buenos Aires, Editorial Siglo XXI. 2014.

MILLER, Michael B, The Bon Marché: Bourgeois Culture and the Department Store, 1869-1920. Princeton, N.J.: Princeton University Press, 1981.

MOULIAN, Tomás, Fracturas: De Pedro Aguirre Cerda a Salvador Allende (1938-1973), Santiago, LOM Ediciones, 2006.

PLATT, Oreste, El Santiago que se fue: apuntes de la memoria, Santiago: Biblioteca Nacional, 1999.

POBLETE TRONCOSO, Moisés, El derecho del trabajo y la seguridad social en Chile, Santiago, Editorial Jurídica, 1949

QUEIROLO, Graciela Amalia, "Vendedoras: género y trabajo en el sector comercial (Buenos Aires, 1910-1950)," Revista Estudos Feministas, vol. 22, no.1, 2014, pp. 29-50. 
REYNOLDS, Nancy, A City Consumed: Urban Commerce, the Cairo Fire, and the Politics of Decolonization in Egypt, Stanford, California: Stanford University Press, 2012.

ROCCHI, Fernando, Chimneys in the Desert: Industrialization in Argentina during the Export Boom Years, 1870-1930, Stanford, Stanford University Press, 2006.

SALAZAR, Gabriel, La enervante levedad histórica de la clase política civil: (Chile, 190o1973), Santiago, Debate, 2015.

SALAZAR, Gabriel; PINTO, Julio, Historia contemporánea de Chile, Santiago, LOM Ediciones, 2002.

SEMÁN, Ernesto, Ambassadors of the Working Class: Argentina's International Labor Activists and Cold War Democracy in the Americas, Durham, Duke University Press, 2017.

SILVA, J. Pablo, "The Origins of White-Collar Privilege in Chile: Arturo Alessandri, Law 6020, and the Pursuit of a Corporatist Consensus, 1933-1938," Labor 3, no. 1 (2006): 87-112.

STECHER, Antonio; GODOY, Lorena; TORO, Juan Pablo, "Condiciones y experiencias de trabajo en la sala de venta de un supermercado. Explorando los procesos de flexibilización laboral en el sector del retail en Chile”, Polis, vol. 9, núm. 27, 2019, pp. 523-550.

VERGARA, Ángela, "Paternalismo industrial, empresa extranjera y campamentos mineros en América Latina: un esfuerzo de historia laboral y transnacional", Avances del Cesor (Rosario, Argentina) 10, no. 10 (2013): 113-128.

VIDELA Bravo, Enzo; VENEGAS VALDEBENITO, Hernán; GODOY ORELLANA, Milton, El orden fabril. Paternalismo industrial en la minería chilena. 1900-1950, Valparaíso, América en Movimiento, 2016.

Cita sugerida: Vergara, Ángela; Orellana, Paola. (2019) "Los trabajadores de las grandes tiendas: Gath y Chaves, Chile, 1910-1952", Claves. Revista de Historia, Vol. 5, No 8, ISSN 2393-6584, pp. 35-65. DOI: http://dx.doi.org/10.25032/crh.v5i8.3 